\title{
Kinematical analysis of emotionally induced facial expressions in patients with obsessive-compulsive disorder ${ }^{1}$
}

\author{
R. MERGL, ${ }^{2}$ M. VOGEL, P. MAVROGIORGOU, C. GÖBEL, M. ZAUDIG, \\ U. HEGERL AND G. JUCKEL \\ From the Department of Psychiatry, Ludwig-Maximilians-Universität München, Laboratory of Clinical \\ Neurophysiology, München; Pfizer Inc., Karlsruhe; Psychosomatic Hospital Windach, Windach; and \\ Department of Psychiatry, Charité, Humboldt Universität zu Berlin, Berlin, Germany
}

\begin{abstract}
Background. Motor function is deficient in many patients with obsessive-compulsive disorder (OCD), especially in the face. To investigate subtle motor dysfunction, kinematical analysis of emotional facial expressions can be used. Our aim was to investigate facial movements in response to humorous film stimuli in OCD patients.
\end{abstract}

Method. Kinematical analysis of facial movements was performed. Ultrasound markers at defined points of the face provided exact measurement of facial movements, while subjects watched a humorous movie ('Mr Bean'). Thirty-four OCD patients (19 male, 15 female; mean (s.D.) age: $35 \cdot 8$ $(11 \cdot 5)$ years; mean (s.D.) total Y-BOCS score: $25 \cdot 5(5 \cdot 9))$ were studied in unmedicated state and after a 10-week treatment with the SSRI sertraline. Thirty-four healthy controls (19 male, 15 female; mean (s.D.) age: $37 \cdot 5(13 \cdot 1)$ years) were also investigated.

Results. At baseline, OCD patients showed significantly slower velocity at the beginning of laughing than healthy controls and a reduced laughing frequency. There was a significant negative correlation between laughing frequency and severity of OCD symptoms. Ten weeks later a significant increase of laughing frequency and initial velocity during laughing was found.

Conclusions. Execution of adequate facial reactions to humour is abnormally slow in OCD patients. Susceptibility of OCD patients with regard to emotional stimuli is less pronounced than in healthy subjects. This phenomenon is closely correlated to OCD symptoms and is state-dependent.

\section{INTRODUCTION}

Obsessive-compulsive disorder (OCD) is a prevalent psychiatric disease (Rasmussen \& Eisen, 1990), with intrusive thoughts (obsessions) and ritualistic repetitive behaviours (compulsions) as the main symptoms. Many OCD patients suffer from motor disturbances: abnormal involuntary movements are found in

\footnotetext{
${ }^{1}$ Presented in part at the 7th World Congress of Biological Psychiatry, Berlin, Germany, 1-6 July 2001.

2 Address for correspondence: Dr Roland Mergl, Department of Psychiatry, Ludwig-Maximilians-Universität München, Laboratory of Clinical Neurophysiology, Nussbaumstrasse 7, D-80336 München, Germany.
}

about one-third of OCD patients, disturbances of fine motor coordination were present in $53.7 \%$ of OCD patients (Hollander et al. 1990; Mavrogiorgou et al. 2001).

As in patients with Parkinson's disease, some of OCD patients have been reported to exhibit abnormal facial activity, including rigidity of the face and a mask-like face (Schilder, 1938). Schilder's case reports are interesting because they suggest the presence of basal ganglia dysfunction in OCD. There are several findings suggestive of this, including brain-imaging reports that show reduced caudate volume in many patients with OCD (Luxenberg et al. 
Table 1. Description of the sample

\begin{tabular}{lccc}
\hline \hline Variables & $\begin{array}{c}\text { OCD patients } \\
(N=34)\end{array}$ & $\begin{array}{c}\text { Healthy controls } \\
(N=34)\end{array}$ & $\begin{array}{c}\text { Intergroup } \\
\text { comparison }\end{array}$ \\
\hline Age (years), mean (s.D.) & $35 \cdot 82(11 \cdot 54)$ & $37 \cdot 53(13 \cdot 08)$ & $t=-0 \cdot 57 \mathrm{NS}$ \\
Gender (male/female) & $19 / 15$ & $19 / 15$ & - \\
Dominant hand (right/left) & $31 / 3$ & $28 / 6$ & $\chi^{2}=0 \cdot 64 \mathrm{NS}$ \\
High school level (yes/no) & $10 / 24$ & $26 / 8$ & - \\
Age at the onset of OCD (years), mean (s.D.) & $22 \cdot 11(12.09)$ & - & - \\
Duration of disease, mean (s.D.) & $13 \cdot 72(9 \cdot 51)$ & - & - \\
Positive family history (yes/no) & $17 / 17$ & & - \\
\hline \hline
\end{tabular}

*** $P<0.001 ;$ NS, not significant.

1988; Robinson et al. 1995), association of OCD with basal ganglia disorders, as in Sydenham's chorea (Swedo et al. 1989) and Tourette syndrome (Pauls et al. 1986), and higher prevalence of motor signs reflecting basal ganglia dysfunction in OCD patients, as compared to healthy controls (Hymas et al. 1998).

Analysis of emotionally induced facial movements is a promising tool for the assessment of abnormal facial activation in OCD. Facial expressions of basic emotions (e.g. joy, anger, disgust) result from movements of the facial muscles that are innervated by the facial nucleus, which is highly connected to the limbic system (Rinn, 1984). The nucleus accumbens, the so-called limbic-motor interface (Mogenson et al. 1980) plays a relevant role in starting motor programmes elicited by emotional processes in the limbic system (Heimer et al. 1982). Since the serotonergic system is involved in the modulation of neuronal excitability of the nucleus accumbens (Filip \& Cunningham, 2002) and of the motor system (Jacobs \& Fornal, 1997) as well as in the pathogenesis of OCD (compare Hegerl \& Mavrogiorgou, 1999), it may be speculated that involuntary motor disturbances in OCD patients may be triggered by disturbances of serotonergic neurotransmission. Other neurotransmitter systems like dopamine (McDougle et al. 1990) might also be involved in these disturbances.

To investigate facial expression in OCD, objective measures are needed, which provide analysis of starting a facial movement. This can be performed by using a new computer-based and very sensitive method (see Juckel \& Polzer, 1998; Padberg et al. 2001), providing the exact registration of the initial velocity of oro-facial (laughing) movements elicited by emotional (humorous) stimuli. In this context, the problematical idiosyncrasies of humour (especially high inter-individual variability of sense of humour) must be taken into account. Laughing has been proposed to be a biological and psychological act that can be found in humans as well as great apes (Provine, 2000). Considering the brain mechanisms of laughter, laughing movements have been induced by electrical stimulation at specific cortical sites including the anterior cingulate and the orbitofrontal cortex (Sem-Jacobsen, 1968), the basal temporal lobe (Arroyo et al. 1993) as well as the anterior part of the supplementary motor area (Fried et al. 1998). Since abnormal or lack of facial responses to emotional stimuli have negative implications to well-being and social interaction (Schulman-Green, 1999) we planned to investigate facial movements in response to humorous film stimuli in healthy subjects and OCD patients tested before and during therapy with a serotonin reuptake inhibitor (sertraline), using a kinematical approach. To our knowledge, it is the first study that examines laughter responses to humorous stimuli in OCD patients with the use of ultrasonic markers.

\section{METHOD}

\section{Subjects}

Thirty-four adult patients, who met DSM-IV criteria for OCD, participated in the study. The healthy controls were volunteers who were asked by mail to participate in our study. Their addresses have been obtained from the registration office. The normal controls were comparable to the patients with regard to age, gender and handedness (Table 1). They were not medicated and they had no DSM-IV diagnosis 
of mental disorders. Exclusion criteria for the healthy subjects included medical disease at study time.

All subjects gave written consent according to the guidelines found in the Declaration of Helsinki (World Medical Association, 1997). At the time of the study all patients were treated in the Psychosomatic Hospital, Windach. The severity of OCD symptoms was assessed using the YaleBrown Obsessive-Compulsive Scale (Y-BOCS) (Goodman et al. 1989a,b), their degree of depression by use of the Hamilton Depression Rating scale (17-item version) (HDRS) (Hamilton \& Guy, 1976) and their severity of disease was evaluated with the Clinical Global Impressions severity and improvement scores (CGI) (Guy, 1976). At baseline, the OCD patients had a mean (s.D.) total Y-BOCS score of $25.5(5 \cdot 9)$, with their score for obsessions being $13.4(3 \cdot 0)$, for compulsions $12 \cdot 1$ (3.7). Their mean (S.D.) HDRS score was $13 \cdot 4(6 \cdot 6)$ and their mean (s.D.) CGI score was $5 \cdot 5(1 \cdot 1)$.

All OCD patients were medication free for 14 days prior to the investigations. No patient had been treated with long-acting psychotropic drugs known to have effects on motor control even several weeks after termination of treatment (e.g. neuroleptics). The OCD patients had neither focal neurological disease nor any other major medical disease at time of the study. Obsessions with respect to laughing, watching films, or being observed or being studied have not been found in the patients' sample.

\section{Study design}

All OCD patients were screened in the first 2 days after admission into the hospital. After baseline, the OCD patients were treated with sertraline (daily oral dose: $50 \mathrm{mg}$; after 4 and 7 weeks, the dose could be raised by $50 \mathrm{mg}$, respectively) and a semi-standardized behaviour therapy (Hauke et al. 1998). Ten weeks later, the facial investigations were repeated.

\section{Kinematical analysis of facial expression}

Analysis of facial movements was performed as described previously (Padberg et al. 2001), using an active device for the measurement of movements (CMS 70; ZEBRIS Ltd., Tübingen, Germany). Special microphones registered highfrequency ultrasonic signals $(35 \mathrm{kHz})$ emitted by special markers. These signals were registered online with a sampling rate maximally of $200 \mathrm{~Hz} /$ number of markers. The digital evaluation of these signals was performed offline, thus allowing the exact, three-dimensional registration of the coordinates of the ultrasonic markers with very high temporal (a few milliseconds) and spatial resolution $(0.1 \mathrm{~mm})$. Disturbing head movements were extracted using one reference marker positioned on a tape at the forehead and serving as a reference to differentiate head from facial movements. The ultrasonic markers were fixed by double-faced adhesive tapes to the right and left corner of the mouth, thus providing registration of facial movements caused by activity of the zygomaticus major and minor, risorius and depressor anguli oris muscles. Two further markers were fixed to the left and right medial inferior rim of the eye to record activity of the orbicularis oculi muscle. All these muscles are innervated by the nervus facialis. The experimenter had been trained to place the markers in the same spots before the start of the study in order to ensure comparability of measurements.

The subject sat on a comfortable chair in front of a device used to record the ultrasonic signals emitted by the facial markers, a videocamera and a television screen (for presentation of the emotional stimuli). Two 'Mr Bean' sketches were shown to induce the positive emotion 'humour'. After presentation of the sketches (maximal duration, $9 \mathrm{~min}$ ), the subject was asked to assess how funny the sketches were, using a visual analogue scale (VAS) ('degree of funniness'; length: $16 \mathrm{~cm}$ ).

During this investigation, facial activity was registered, using the ultrasonic measurement system and simultaneously video-recording of the subject's face was performed in order to assign the emotional reactions to the kinematical data exactly. In order to draw a clear dividing line between involuntary facial activity elicited by emotional stimuli ('Mr Bean') and voluntary movements of the mouth angles and the eyes, the subjects were asked to stretch their mouth angles and to close their eyes tightly after presentation of the sketches. After the investigation, the humorous movie, video-recording of the face and facial activity, as measured by the ultrasonic markers, were synchronized using a frame code generator, thus allowing exact analysis 


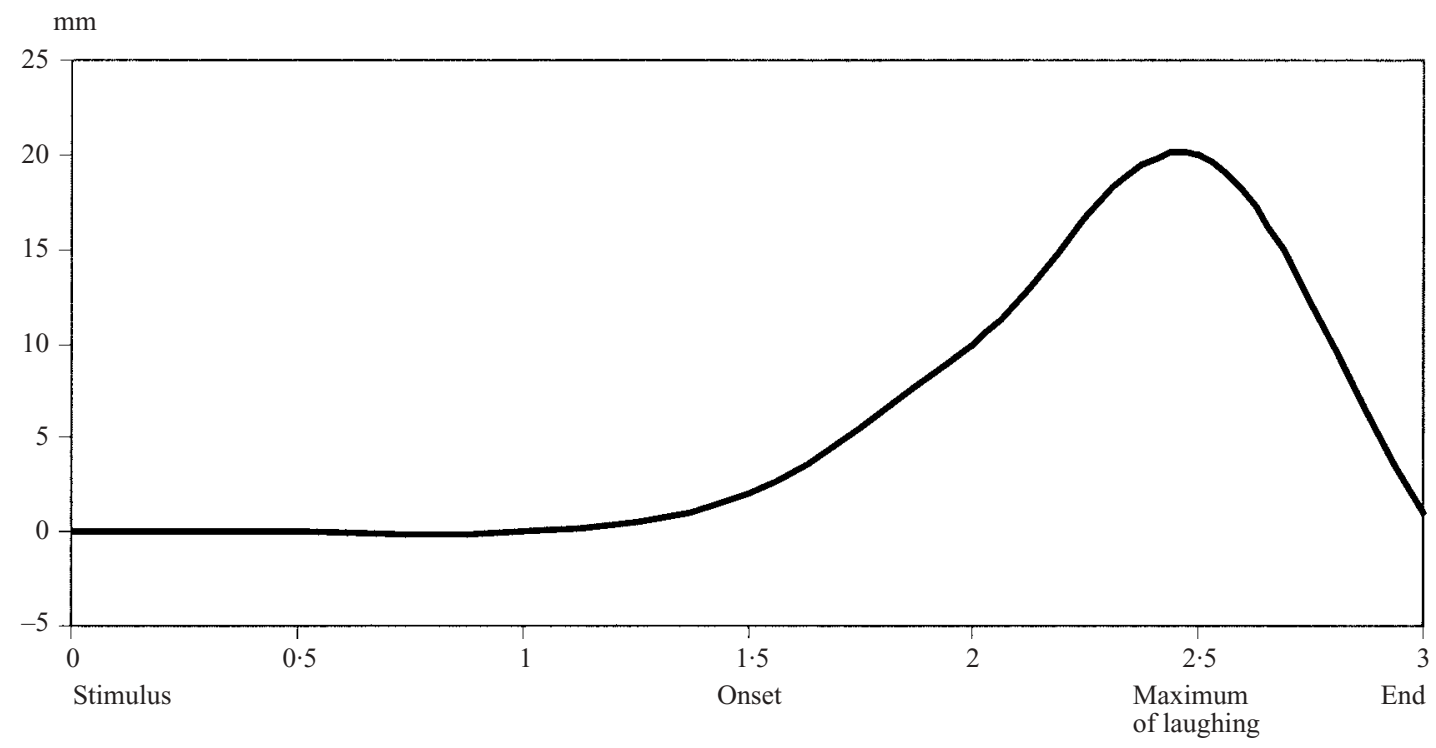

FIG. 1. Schematic representation of laughing movements after presentation of an emotional stimulus.

of the dynamics of laughing facial movements closely connected to the emotional stimuli.

Offline analysis of facial activity has been established by a special computer software (3DA). The digitalized signals of each ultrasonic marker were graphically represented as a spatiotemporal function and filtered. Artefacts have been corrected; a special algorithm representing sliding averaging of data during simultaneous data recording (compare Hermsdörfer et al. 1996) provided valid filtering of the data. 'Laughing' has been evaluated in five film sequences by visually detecting synchronous changes of facial activity in the video-recordings and subsequent kinematical analyses of facial movements in the correspondent time interval. Three independent normal raters had previously assessed these film sequences to be especially humorous by use of a visual analogue scale. The laughing movement can be graphically represented as a spatio-temporal measuring curve using 3DA (Fig. 1).

In a first step, frequency of laughing, the number of laughing reactions to the movie, related to the length of the movie $(\mathrm{N} / \mathrm{min}$ movie), has been determined for each subject. In a second step, the movements of the markers, corresponding to 'laughing' (controlled by a simultaneous video-recording of the face) have been analysed. The following kinematical main variables shown to be sensitive indicators of facial movements elicited by positive emotion in previous studies (e.g. Juckel et al. 1999; Padberg et al. 2001; Juckel, 2002) have been computed for each marker using 3DA: the initial velocity of the laughing movement, defined as the velocity $(\mathrm{mm} / \mathrm{s})$ of each marker at the beginning of laughing and calculated as slope through the start and maximum (space and time) point of the laughing movement (mean of three); emotional reaction time (ERT) i.e. time between a humorous stimulus in the film (as defined by healthy subjects prior to the study) and the reaction, i.e. onset of a laughing movement of the left and right corner of the mouth (mean of five humorous stimuli per movie) (in seconds).

\section{Statistical evaluation}

Mean kinematical parameters of facial expression were analysed separately, using the statistical package SPSS for Windows (version 10.0). The dependent variables were submitted to a $2 \times 2$ analysis of variance (MANOVA), in order to compare between two groups (OCD patients, healthy controls) with respect to the corner of the mouth and the rim of the eye (left, right). Greenhouse-Geisser correction of the degrees of freedom was applied. Main effects of 
Table 2. Mean facial parameter scores for the right and left side by diagnostic group

\begin{tabular}{|c|c|c|c|c|c|c|}
\hline \multirow[b]{2}{*}{ Initial velocity $(\mathrm{mm} / \mathrm{s})$} & \multicolumn{2}{|c|}{ OCD patients $(N=34)$} & \multicolumn{2}{|c|}{ Healthy controls $(N=34)$} & \multirow[b]{2}{*}{$\begin{array}{c}\text { Group } \\
\quad P\end{array}$} & \multirow[b]{2}{*}{$\begin{array}{c}\text { Group } \times \text { side } \\
P\end{array}$} \\
\hline & $\begin{array}{c}\text { Right } \\
\text { Mean (s.D.) }\end{array}$ & $\begin{array}{c}\text { Left } \\
\text { Mean (s.D.) }\end{array}$ & $\begin{array}{c}\text { Right } \\
\text { Mean (S.D.) }\end{array}$ & $\begin{array}{c}\text { Left } \\
\text { Mean (s.D.) }\end{array}$ & & \\
\hline Mouth angle marker (laughing) & $5 \cdot 76(3.03)$ & $5 \cdot 64(2 \cdot 75)$ & $8 \cdot 57(5 \cdot 67)$ & $8 \cdot 26(4 \cdot 12)$ & $* *$ & NS \\
\hline Stretching of the mouth angles & $18 \cdot 51(9 \cdot 63)$ & $16 \cdot 94(7 \cdot 08)$ & $22 \cdot 14(14 \cdot 99)$ & $20 \cdot 64(15 \cdot 20)$ & NS & NS \\
\hline Eye marker (laughing) & $3.50(1.83)$ & $3.66(1.85)$ & $5 \cdot 33(2 \cdot 72)$ & $5 \cdot 35(2 \cdot 11)$ & $* *$ & NS \\
\hline Tight closing of the eyes & $18.84(7.66)$ & $18.85(8.73)$ & $22 \cdot 34(11 \cdot 89)$ & $21 \cdot 42(11 \cdot 39)$ & NS & NS \\
\hline
\end{tabular}

Two-way variance analysis for repeated measures was computed for the initial velocity of facial movements.

** $P<0 \cdot 01$; NS, not significant.

the group reflect abnormal facial activity, group and side interactions indicate abnormal motor asymmetries in patients with OCD.

The influence of age, age at the onset of OCD and the duration of disease on kinematical parameters of facial expression was studied by means of Pearson's correlation. We also computed Spearman-Brown correlations between clinical rating scale scores (Y-BOCS, HAMD17, CGI total scores) and the initial velocity of laughing. Chi-square analysis was performed in order to answer the question whether the initial velocity of laughing is independent from gender or family history of psychiatric disease.

Changes of facial activity during treatment were studied in OCD patients by applying $t$ tests for paired samples (baseline versus 10th week).

In view of the number of main outcome measures (initial velocity of laughing, emotional reaction time and laughing frequency) raising the statistical problem of multiple comparisons, in all statistical analyses, the significance level was alpha-adjusted and taken at $0 \cdot 0167(0 \cdot 05 / 3)$.

\section{RESULTS}

\section{OCD patients versus healthy controls}

\section{Initial velocity of laughing and voluntary facial movements}

Mean kinematical scores of facial expression (initial velocity of different facial movements) are represented in Table 2. Analysis of variance (compare Table 2) and post hoc $t$ tests revealed that OCD patients exhibited significantly slower initial velocities of involuntary facial movements ('laughing') than healthy controls (left eye, $t(1,45)=-2 \cdot 83, P=0 \cdot 007$; right eye, $t(1,45)=$ $-2.56, P=0.014$; left angle of the mouth, $t(1,66)=-3.08, P=0.003$; right angle of the mouth $t(1,66)=-2 \cdot 55, \quad P=0 \cdot 013) \quad($ Fig. 2), while the group differences in voluntary movements (closing of the eyes; stretching of the mouth angles) were not significant $(-1 \cdot 14 \leqslant$ $t(1,40 \leqslant 56) \leqslant-0 \cdot 83 ; 0 \cdot 26 \leqslant P \leqslant 0 \cdot 42)$.

Regarding motor asymmetries (differences between right and left markers in the initial velocity of movements of the face), anomalous side differences could not be found for patients with $\mathrm{OCD}$, as reflected by non-significant group $\times$ side interactions in the MANOVA (Table 2).

In line with these results, post hoc $t$ tests for paired samples did not reveal any significant differences between right and left markers for the initial velocity of facial movements under different task conditions (laughing, stretching of the mouth angles, tight closing of the eyes) for patients with OCD $(-1 \cdot 40 \leqslant t(18 \leqslant 33) \leqslant 1 \cdot 39$; $0 \cdot 17 \leqslant P \leqslant 0 \cdot 996)$ and healthy controls $(-1 \cdot 25 \leqslant$ $t(21 \leqslant 33) \leqslant 0 \cdot 05 ; 0 \cdot 23 \leqslant P \leqslant 0 \cdot 96)$.

\section{Emotional reaction time}

Differences between OCD patients and healthy controls regarding emotional reaction time were not significant (left corner of the mouth, $t(1,65)=-0 \cdot 89, P=0 \cdot 38$; right corner of the mouth, $t(1,65)=-1.03, P=0.31)$, with the OCD patients exhibiting somewhat lower values (mean ERT for the left corner of the mouth $(\mathrm{s} . \mathrm{D})=.1.20 \quad(0.53) \mathrm{s}$; right corner of the mouth $=1 \cdot 19(0 \cdot 53) \mathrm{s})$ than the healthy controls (mean ERT for the left corner of the mouth $($ s.D. $)=1.33(0.63) \mathrm{s} ;$ right corner of the mouth $=$ $1 \cdot 34(0 \cdot 64) \mathrm{s})$.

\section{Laughing frequency}

The mean VAS scores were comparable in OCD (mean VAS score (S.D.) $=10 \cdot 03(3 \cdot 39)$; range, $2 \cdot 4-15 \cdot 5$ ) and healthy subjects (mean VAS score 


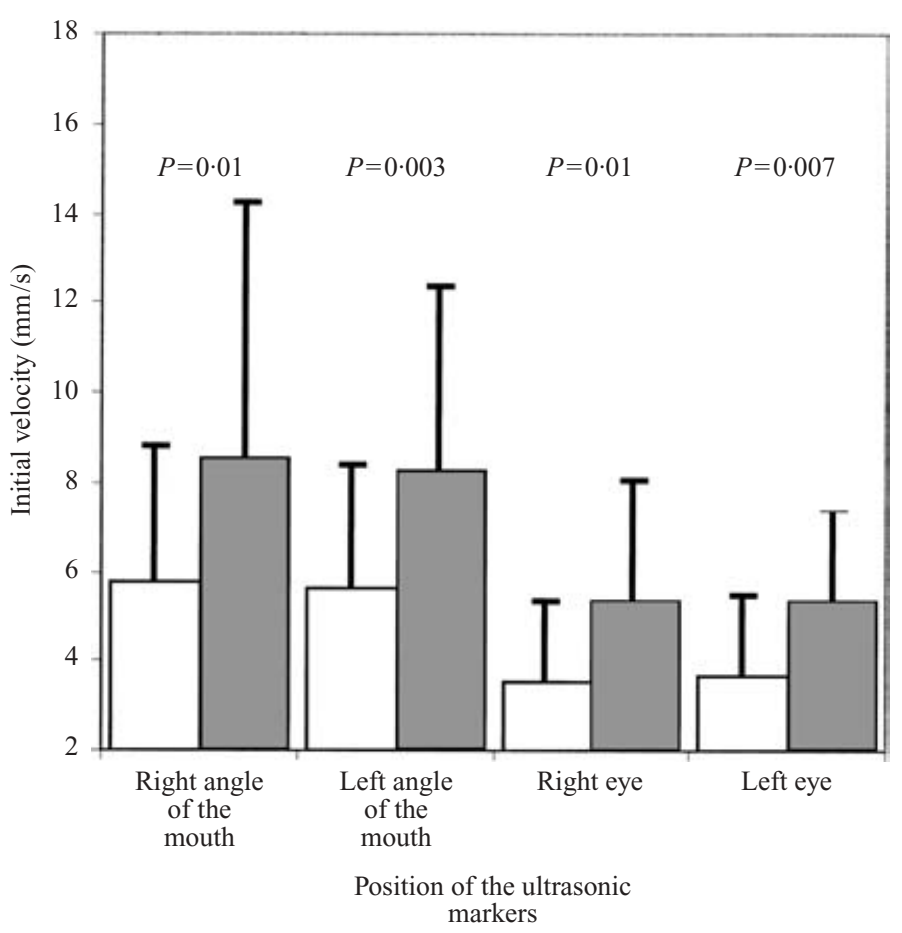

FIG. 2. Mean (s.D.) initial velocity of laughing movements elicited by watching of a humorous movie ('Mr Bean') in 34 patients with OCD $(\square)$ and 34 healthy controls $(\square)$, as measured by use of ultrasonic markers at different positions of the face (right and left angle of the mouth; medial inferior rims of the left and the right eye). $P$ values indicate that healthy subjects laughed significantly faster than OCD patients in this situation.

(s.D.) $=11 \cdot 32(3 \cdot 20) ;$ range, $0 \cdot 2-15 \cdot 1)$, suggesting that both groups assessed the movies to be humorous in similar intensity $(t(1,64)=-1 \cdot 59$, $P=0 \cdot 12$ ). However, frequency of laughing reactions was significantly lower in OCD patients (mean laughing frequency (S.D.) $=13 \cdot 85(7 \cdot 79)$; range, 3-26), as compared to healthy controls (mean laughing frequency (s.D.) $=24 \cdot 41(10 \cdot 15)$; range, $3-45)(t(1,66)=-4 \cdot 81, P \leqslant 0 \cdot 001)$.

Besides the documented statistically significant differences, there was no clinical or interpersonal significance noted in the differences in facial movements found with this ultrasound technique (like sense of oddness on patient recruitment that might reflect decreased 'humorous stimuli' responses).

\section{Correlation of facial movements with demographic and clinical factors in patients with OCD symptoms}

In OCD patients, Pearson's correlations between facial and emotional parameters (VAS, emotional reaction time, laughing frequency and initial velocity of different facial movements) and three other variables (age, age at onset of disease and duration of OCD) indicated that there was no significant association between these variables (age, $-0 \cdot 24 \leqslant r_{p} \leqslant 0 \cdot 35$; $0 \cdot 13 \leqslant P \leqslant 0 \cdot 87$; age at onset of disease, $-0 \cdot 20 \leqslant r_{p} \leqslant 0 \cdot 29 ; 0 \cdot 22 \leqslant P \leqslant 0 \cdot 93$; duration of OCD,$\left.-0 \cdot 23 \leqslant r_{p} \leqslant 0 \cdot 23 ; 0 \cdot 20 \leqslant P \leqslant 0 \cdot 84\right)$.

In line with these findings, comparison of 17 OCD patients with early onset of disease $(<21$ years) with 17 OCD patients with later onset of OCD ( $>21$ years) demonstrated that both groups exhibited comparable aspects of facial expression $(-1 \cdot 29 \leqslant t(1,17 \leqslant 32) \leqslant 1.91$; $0 \cdot 07 \leqslant P \leqslant 0 \cdot 93$ ).

As revealed by $t$ tests for independent samples the effects of gender, educational level and family history of psychiatric disease on facial parameters (including VAS) were rather low in patients with OCD (gender, $-0.92 \leqslant$ $t(1,17 \leqslant 32) \leqslant 1 \cdot 32 ; 0 \cdot 20 \leqslant P \leqslant 0 \cdot 95 ;$ high school 
level, $\quad-0 \cdot 83 \leqslant t(1,17 \leqslant 31) \leqslant 1 \cdot 19 ; \quad 0 \cdot 24 \leqslant P \leqslant$ 0.87 ; family history of psychiatric disease, $-1 \cdot 54 \leqslant t(1,17 \leqslant 32) \leqslant 1 \cdot 76 ; 0 \cdot 09 \leqslant P \leqslant 0 \cdot 97)$.

Baseline scores on psychopathological rating scales (Y-BOCS, HAMD-17, CGI) were correlated with facial parameters by Spearman's analysis. The higher the total baseline Y-BOCS score, the lower the laughing frequency $\left(r_{s}=\right.$ $-0.43, P=0.011)$ and the higher the initial velocity of voluntary movements of the right angle of the mouth $\left(r_{s}=0.43, P=0.02\right)$. The latter variable showed also significantly positive correlation with the baseline Y-BOCS scores for the intensity of obsessions $\left(r_{s}=0 \cdot 40, P=0 \cdot 02\right)$. Moreover, there were significant negative Spearman-Brown correlations between the total baseline Y-BOCS score for the severity of compulsions and the visual analogue scale $\left(r_{s}=\right.$ $-0.45, P=0.008)$ and the laughing frequency at baseline $\left(r_{s}=-0 \cdot 52, P=0 \cdot 002\right)$.

The total baseline HAMD-17 score did not significantly correlate with parameters of facial movements $\left(-0 \cdot 18 \leqslant r_{s} \leqslant 0 \cdot 34 ; 0 \cdot 06 \leqslant P \leqslant 0 \cdot 99\right)$. The higher the baseline CGI score, the lower laughing frequency at baseline $\left(r_{s}=-0 \cdot 46\right.$, $P=0.006)$. Other significant associations between the baseline CGI score and variables of facial expression could not be detected.

\section{DISCUSSION}

\section{Interpretations}

\section{Abnormal facial expression in patients with $O C D$}

We have shown that OCD patients exhibited significantly slower initial velocities of involuntary laughing movements than healthy controls, with initial velocity of voluntary facial movements (like closing of the eyes) being comparable in both groups. Patients with OCD and healthy controls did not significantly differ in laterality of voluntary or involuntary facial movements. So, distinctive facial features seem not to be restricted to one side in patients with OCD.

Emotional reaction time and judgements of the humour of the movie cannot account for slower initial velocity of involuntary facial movements in OCD patients because they were comparable with the normal controls. One could assume that slower reactions on emotional stimuli in OCD ('subcortical' laughing) resulted from disturbances of attention. However, this explanation is not convincing because there were no significant differences between OCD patients and healthy controls in the initial velocity of voluntary facial movements in 'cortical' tasks (e.g. stretching of the mouth angles). Instead, level of education, which was much higher in healthy subjects as compared to OCD patients, might represent an important confounding variable. However, it must be emphasized that slower facial reactions on film stimuli in OCD patients were independent of the level of education.

Further analysis revealed that all subjects (patients and controls) were susceptible regarding humour (minimum laughing frequency $=3$ ). However, healthy subjects laughed significantly more frequently than OCD patients in the experimental situation. OCD patients seemed to be less susceptible than healthy controls with regard to emotional stimuli. Laughing frequency and initial velocity of 'laughing' movements were not significantly correlated in OCD patients. Therefore, they seem to reflect different aspects of abnormal facial expression: low susceptibility regarding emotional stimuli and abnormally slow execution of adequate motor reactions on humorous stimuli. The latter finding may reflect hypomimia (low degree of involuntary movements of the face) as part of a parkinsonoid in subclinical intensity. In fact, older studies (Schilder, 1938) suggest that hypomimia is a quite frequent symptom in OCD patients.

Transformation of the feeling of 'humour' into the motor reaction 'laughing' itself was not disturbed in OCD patients (as indicated by normal emotional reaction time). The morphological substrate of this process might be the nucleus accumbens, the so-called limbic-motor interface (Mogenson et al. 1980). Since the commencement of these motor programmes seems to be comparable in OCD patients and healthy controls, it is unlikely that functional disturbances exist of the limbic-motor interface in OCD patients. In fact, functional disturbances or structural lesions of the nucleus accumbens have, so far, not been reported in OCD patients.

Instead, it can be assumed that basal ganglia dysfunction underlies disturbances of facial expression (especially hypomimia) in OCD patients since hypomimia is a well-known 
phenomenon in patients with Parkinson's disease. Moreover, several studies suggest that basal ganglia dysfunction is an important factor in the pathophysiology of OCD (Saxena et al. 1998). However, it is also important to account for the role of transmitter systems in OCD pathophysiology: serotonin (Hegerl \& Mavrogiorgou, 1999); dopamine (McDougle et al. 1990); and acetylcholine (Lucey et al. 1993).

\section{Correlates of abnormal facial expression in patients with $O C D$}

The initial velocity of facial reactions on emotional stimuli was independent from age, gender, educational level and some clinical variables, namely duration of OCD, age at onset of OCD, family history of psychiatric disease and severity of depression in OCD. However, higher severity of disease (higher baseline CGI score) went along with lower laughing frequency at baseline. The latter variable was also associated with the Y-BOCS score. Higher initial velocity of voluntary movements of the right angle of the mouth was associated with higher intensity of obsessions. However, this finding should be interpreted with much caution because it was a single finding and correlation was rather low $\left(r_{s} \leqslant 0 \cdot 43\right)$.

Overall, initial velocity of involuntary 'laughing' movements of the face seems to be independent from psychopathology in OCD patients. In contrast, laughing frequency was found to be closely associated with OCD symptoms. Therefore, susceptibility regarding emotional stimuli seems to be lower in OCD patients who are severely ill compared to patients with OCD symptoms of mild to moderate severity.

\section{Changes of facial movements}

In an exploratory analysis, changes of facial movements during treatment with sertraline and behavioural therapy in OCD patients had been analysed and a significant increase of laughing frequency $(P<0 \cdot 001)$, emotional reaction time $(P<0.05)$ and the initial velocity of involuntary movements of the right eye during laughing $(P<0.05)$ had been found. Moreover, the amount of clinical remission (as reflected by positive Y-BOCS difference scores) was related to increase in the initial velocity of 'laughing' movements of the left eye $\left(r_{s}=0.35, P<0.05\right)$ in patients with OCD.

\section{Facial muscle function in $O C D$ and other psychiatric diseases}

Overall, our results (normal emotional reaction time, low laughing frequency, slower initial velocity of involuntary facial movements, but normal initial velocity of voluntary facial movements in patients with OCD) primarily reflect hypomimia in OCD patients. In this regard, relevant differences between OCD patients, schizophrenic patients and patients with depression are apparent: unmedicated schizophrenic patients exhibited significantly faster initial velocity of laughing than controls (Juckel et al. 1999), with this finding representing the phenomenon of facial disintegration (Heimann \& Spoerri, 1957). In contrast, depressed patients were characterized by slower initial velocity of voluntary and involuntary facial movements (Juckel, 2002) that reflect psychomotor retardation. The latter phenomenon is quite frequent in patients with depression (compare Sabbe \& Hulstijn, 2001). Our results suggest that only involuntary movements of the face are essentially disturbed in OCD patients, these disturbances are not an epiphenomenon of depression in OCD and they do not resemble the signs of facial disintegration in schizophrenic patients.

\section{Limitations}

Our findings are interesting, but should be viewed with caution. First, humour is a phenomenon with problematic idiosyncrasies and it is well-known that responses to humorous movies vary considerably with individuals. Secondly, since both sertraline and semi-standardized behaviour therapy were given over our 10-week study, it is impossible to know if sertraline had any independent effect, let alone how much of the effect was actually related to serotonin function. In order to clarify how much of the apparent increase in facial muscle movements could be accounted for simply by the passage of time, or the fact that a different film was shown at baseline and 10 weeks later, it would have been necessary to retest the healthy volunteers. In addition, the lack of an adequate placebo treatment group (like placebo pill and 
waiting-list behaviour therapy) or untreated patient controls does not allow us to conclude that a serotonin-enhancing therapy induced follow-up changes of facial parameters in OCD. Also, the OCD patients were admitted for the total duration of the study (10 weeks), which might have affected their response to humour. In summary, it is not clear whether practice, film version or treatment are responsible for the follow-up changes of facial expression in OCD patients. Further methodological limits of our study that need more investigation are: our sample size was quite small; and, we did not directly compare OCD patients with other psychiatric or neurological patient populations.

\section{Future directions}

Further studies of OCD subgroups are needed to develop a more differentiated picture of emotionally induced facial expressions in OCD patients. To examine whether basal ganglia dysfunction represents the morphological substrate of abnormal facial expression in OCD, it will be important to investigate the association of kinematical parameters of facial expression with findings from brain imaging. Finally, another study with a more rigorous design (double-blind, placebo-controlled, randomized; OCD patients and healthy controls tested twice with half the group being shown one film version and the other half the other version) should be conducted to address the question of whether follow-up changes of facial movements in OCD patients are due to serotonin-enhancing therapy.

This study was kindly supported by Pfizer Germany, Inc. The evaluation of the present data was performed by Michael Vogel as part of his M.D. thesis. We gratefully acknowledge the staff of the Psychosomatic Hospital Windach as well as the OCD patients and healthy subjects for their willingness to participate in our study.

\section{REFERENCES}

Arroyo, S., Lesser, R. P., Gordon, B., Uematsu, S., Hart, J., Schwerdt, P., Andreasson, K. \& Fisher, R. S. (1993). Mirth, laughter and gelastic seizures. Brain 116, 757-780.

Filip, M. \& Cunningham, K. A. (2002). Serotonin 5-HT(2C) receptors in nucleus accumbens regulate expression of the hyperlocomotive and discriminative stimulus effects of cocaine. Pharmacology, Biochemistry and Behavior 71, 745-756.

Fried, I., Wilson, C. L., MacDonald, K. A. \& Behnke, E. J. (1998). Electric current stimulates laughter. Nature 391, 650.
Goodman, W. K., Price, L. H., Rasmussen, S. A., Mazure, C., Fleischmann, R. L., Hill, C. L., Heninger, G. R. \& Charney, D. S. $(1989 a)$. The Yale-Brown Obsessive-Compulsive Scale. I. Development, use and reliability. Archives of General Psychiatry 46, 1006-1011.

Goodman, W. K., Price, L. H., Rasmussen, S. A., Mazure, C., Delgado, P., Heninger, G. R. \& Charney, D. S. (1989b). The YaleBrown Obsessive-Compulsive Scale. II. Validity. Archives of General Psychiatry 46, 1012-1016.

Guy, W. (1976). ECDEU Assessment Manual for Psychopharmacology. Department of Health, Education and Welfare: Washington, DC.

Hamilton, M. \& Guy, W. (1976). Hamilton Depression Scale. Beltz: Berlin.

Hauke, W., Ruppert, S., Unger, H., Manzinger, H., Schlehlein, B. \& Zaudig, M. (1998). Multimodale stationäre Verhaltenstherapie bei Zwangsstörungen-Teil 2: Die therapeutische Praxis. Psychotherapie in Psychiatrie, Psychotherapeutischer Medizin und Klinischer Psychologie 3, 224-233.

Hegerl, U. \& Mavrogiorgou, P. (1999). Die Zwangsstörung aus neurobiologischer Sicht. Verhaltenstherapie und Verhaltensmedizin 20, 435-447.

Heimann, H. \& Spoerri, T. (1957). Das Ausdruckssyndrom der mimischen Desintegrierung bei chronischen Schizophrenen. Schweizer Medizinische Wochenschrift 35/36, 1126-1132.

Heimer, L., Switzer, R. D. \& Van Hoesen, G. W. (1982). Ventral striatum and ventral pallidum; components of the motor system? Trends in Neurosciences 5, 83-87.

Hermsdörfer, J., Wack, S., Mai, N. \& Marquardt, C. (1996). Dreidimensionale Bewegungsmessung zur Analyse der Handfunktion. EKN - Entwicklungsgruppe Klinische Neuropsychologie: München.

Hollander, E., Schiffman, E., Cohen, B., Rivera-Stein, M. A., Rosen, W., Gorman, J. M., Fyer, A. J., Papp, L. \& Liebowitz, M. R. (1990). Signs of central nervous system dysfunction in obsessive-compulsive disorder. Archives of General Psychiatry 47, 27-32.

Hymas, N. F. S. (1998). The neurology of obsessive-compulsive disorder. CNS Spectrums 3, 22-28.

Jacobs, B. L. \& Fornal, C. A. (1997). Serotonin and motor activity. Current Opinion in Neurobiology 7, 820-825.

Juckel, G. (2003). Beeinträchtigungen von Mimik und Emotionsausdruck bei affektiven Störungen. In Bewegungsstörungen bei psychischen Erkrankungen (ed. T. Jahn and H. Förstl). Springer: Heidelberg. (In the press.)

Juckel, G. \& Polzer, U. (1998). Fine analysis of abnormal facial expressions in chronic schizophrenic patients - a pilot study. German Journal of Psychiatry 1, 6-9.

Juckel, G., Präßl, A., Froschmayer, S., Mavrogiorgou, P., Tigges, P., Möller, H.-J. \& Hegerl, U. (1999). 'Im Gesicht lesen lernen' Mimikanalyse schizophrener Patienten. In Schizophrenie-eine affektive Erkrankung? (ed. W. Machleidt, H. Haltenhof and P. Garlipp), pp. 127-134. Schattauer: Stuttgart.

Lucey, J. V., Butcher, G., Clare, A. W. \& Dinan, T. G. (1993). Elevated growth hormone responses to pyridostigmine in obsessive-compulsive disorder: evidence of cholinergic supersensitivity. American Journal of Psychiatry 150, 961-962.

Luxenberg, J. S., Swedo, S. E., Flament, M. F., Friedland, R. P., Rapoport, J. L. \& Rapoport, S. I. (1988). Neuroanatomical abnormalities in obsessive-compulsive disorder. American Journal of Psychiatry 145, 1089-1093.

McDougle, C. J., Goodman, W. K., Price, L. H., Delgado, P. L., Krystal, J.H., Charney, D. S. \& Heninger, G. R. (1990). Neuroleptic addition in fluvoxamine-refractory obsessivecompulsive disorder. American Journal of Psychiatry 147, 650-654.

Mavrogiorgou, P., Mergl, R., Tigges, P., El Husseini, J., Schröter, A., Juckel, G., Zaudig, M. \& Hegerl, U. (2001). Kinematical analysis of handwriting movements in patients with obsessivecompulsive disorder. Journal of Neurology, Neurosurgery and Psychiatry 70, 605-612. 
Mogenson, G. J., Johnes, D. L. \& Yim, C. C. (1980). From motivation to action: functional interface between the limbic system and the motor system. Progress in Neurobiology 14, 69-97.

Padberg, F., Juckel, G., Präßl, A., Zwanzger, P., Mavrogiorgou, P., Hegerl, U., Hampel, H. \& Möller, H.-J. (2001). Prefrontal cortex modulation of mood and emotionally induced facial expressions: a transcranial magnetic stimulation study. Journal of Neuropsychiatry and Clinical Neurosciences 13, 206-212.

Pauls, D. L., Towbin, K. E., Leckman, J. F., Zahner, G. E. \& Cohen, D. J. (1986). Gilles de la Tourette's syndrome and obsessivecompulsive disorder. Evidence supporting a genetic relationship. Archives of General Psychiatry 43, 1180-1182.

Provine, R. R. (2000). Laughter-A Scientific Investigation. Viking: New York.

Rasmussen, S. A. \& Eisen, J. L. (1990). Epidemiology of obsessivecompulsive disorder. Journal of Clinical Psychiatry 51 (suppl.), $10-13$.

Rinn, W. E. (1984). The neuropsychology of facial expression - a review of neurological and psychological mechanisms for producing facial expressions. Psychological Bulletin 95, 52-77.

Robinson, D., Wu, H., Munne, R. A., Ashtari, M., Alvir, J. M., Lerner, G., Koreen, A., Cole, K. \& Bogerts, B. (1995). Reduced caudate nucleus volume in obsessive-compulsive disorder. Archives of General Psychiatry 52, 393-398.
Sabbe, B. \& Hulstijn, W. (2001). Psychomotor disturbances in schizophrenia and depressive disorders. Current Opinion in Psychiatry 14, 597-603.

Saxena, S., Brody, A. L., Schwartz, J. M. \& Baxter, L. R. (1998). Neuroimaging and frontal-subcortical circuitry in obsessivecompulsive disorder. British Journal of Psychiatry 35 (suppl.), 26-37.

Schilder, P. (1938). The organic background of obsessions and compulsions. American Journal of Psychiatry 94, 1397-1416.

Schulman-Green, D. J. (1999). Deceiving appearances. Communicating with facially inexpressive older adults. Journal of Gerontology and Nursing 25, 40-43.

Sem-Jacobsen, C. W. (1968). Changes in mood. In Depth-electrographic Stimulation of the Human Brain and Behavior (ed. W. H. Gantt), pp. 127-138. Charles C. Thomas: Springfield.

Swedo, S. E., Rapoport, J. L., Cheslow, D. L., Leonard, H. L., Ayoub, E. M., Hosier, D. M. \& Wald, E. R. (1989). High prevalence of obsessive-compulsive symptoms in patients with Sydenham's chorea. American Journal of Psychiatry 146 246-249.

World Medical Association (1997). World Medical Association declaration of Helsinki. Recommendations guiding physicians in biomedical research involving human subjects. Journal of the American Medical Association 277, 925-926. 